\title{
DETECTION OF BOVINE ADENOVIRUSE-3 (BAV-3) FROM CALVES IN NINEVEH PROVINCE
}

\author{
ABDULHAKIM AMER SHEET and SAFWAN YOUSUF ALBAROODI \\ ${ }^{1}$ Department of Microbiology, Collage of Veterinary Medicine, University of Msoul, Msoul, Iraq \\ ${ }^{2}$ Department of Preventive and Internal Medicine, Collage of Veterinary Medicine, \\ University of Msoul, Msoul, Iraq
}

Received: 22 January 2019; Accepted: 16 February 2019

\begin{abstract}
A total of 200 samples of blood samples were collected for the serum of 200 animals of all ages and origin, to investigate antibodies and antigens of the bovine adenovirus. The results of the immunosorbent enzyme-specific immunosorbent testing to detect the specialized antibodies of the virus showed that the overall infection rate was 28\%; while the highest incidence was for the 6-9 age Months group (53.3\%). The results of the study showed that the severity of the infection and according to the criteria used to calculate them in the instructions of the manufacturer of the test, that the highest rate of infection of calves is greater than one and a half years (19.4\%) and that there are significant differences between the younger group and the rest of the groups. (31.6\%) of the local population $(17.7 \%)$ and significant differences in the percentage of infection $(31.6 \%)$.
\end{abstract}

Key words: Bovine adenovirus, antibodies, antigens, calves.

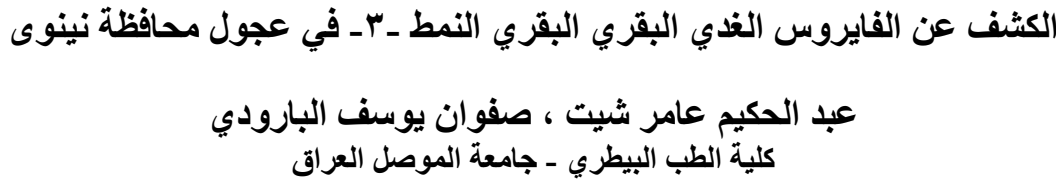

E-mail: laythalkattan@yahoo.com Assiut University web-site: www.aun.edu.eg

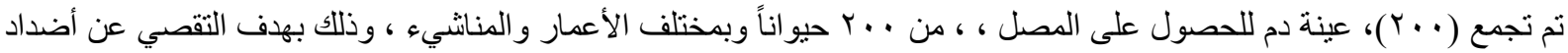

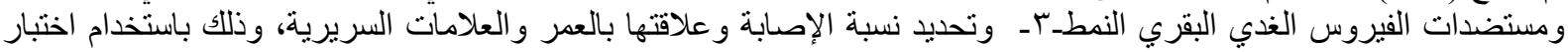

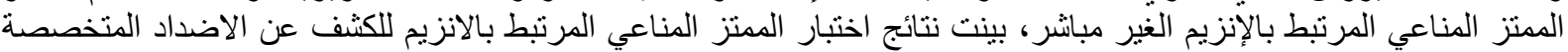

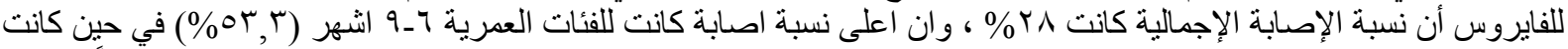

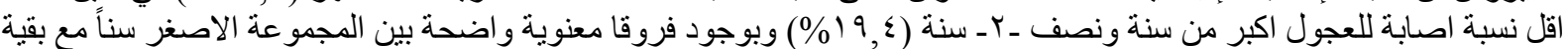

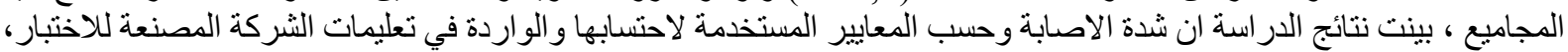

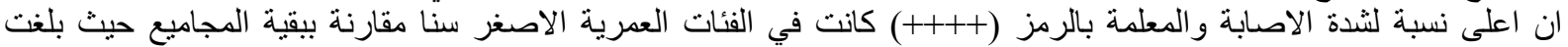

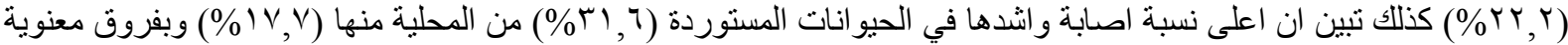

\section{INTRODUCTION \\ المقدمـــــة}

ينتمي الفيروس الغدي البقري النمط ـ- Bovine adenoviruse type 3 (BAV-3) إلى جنس Mastadenovirus من عائلة (Zhang et al., 2017) Adenoviridae

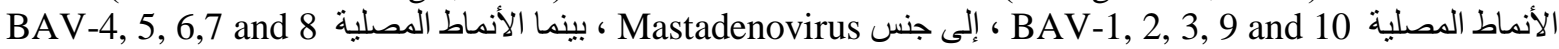
تنتمي إلى جنس Kulshreshtha., 2009) Adenovirus) تلتقسم هذه الأنماط المصلية العشرة للفايروس إلى مجمو عتين فر عيتين 


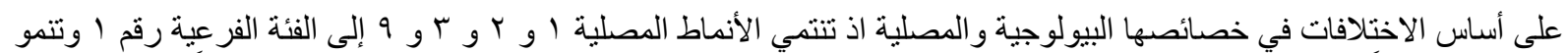

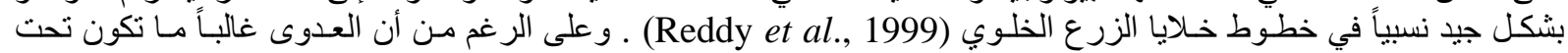

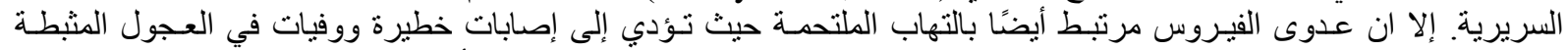

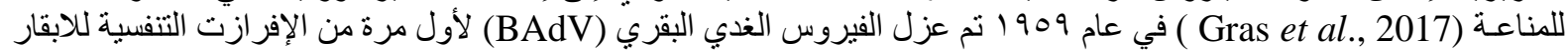
(Makadiya., 2013)

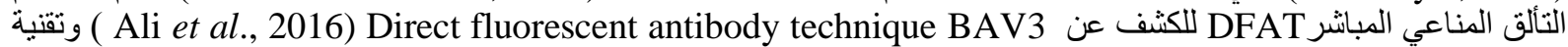

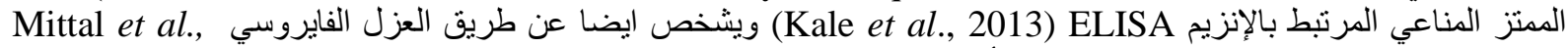
(1996) الفيروسات الغدية له القدره على إصابة أنو اع مختلفه من المضائف وتنز ايد بحدوث الاصنابه.

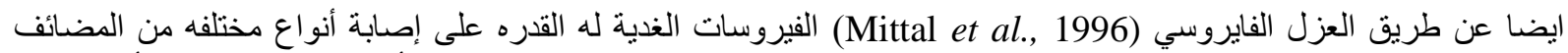

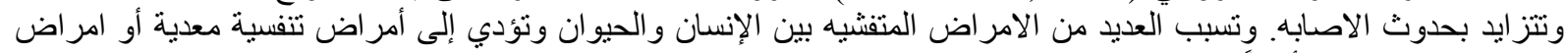

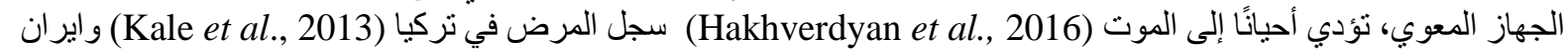

(Sakhaee et al., 2009)

(Giangaspero et al., 1992 ( وايضا سجل المرض في سوريا (Al-Hammadi and Hemida., 2014)

$$
\text { اهداف الدراسة }
$$

لغرض الكثف عن وجود الفيروس في عجول محافظة نينوى وضعت هذه الاراسة للاهداف التالية: الكثف عن اضداد الفبروس الغدي البقري النمط ـ ـ ـ من عجول الأبقار بواسطة اختبار الممتز المناعي المرتبط بالانزيم غير المباثر.

\section{MATERIALS AND METHODS المواد و الطر ائق}

حيوانات الاراسة

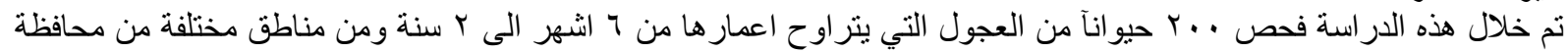

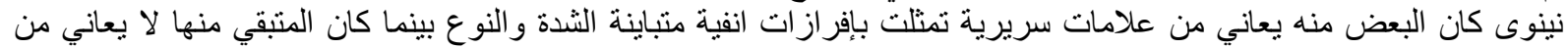

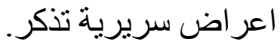

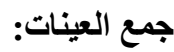

عينات الام

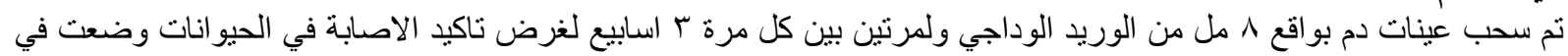

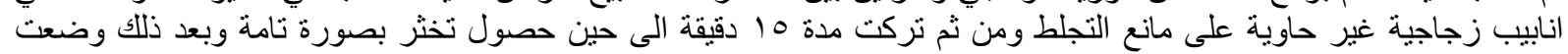

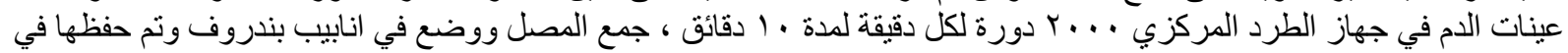

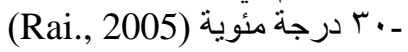

الاختبارات المصلية

تقنية الممتز المناعي المرتبط بالاتزيم: تم أستخدام العدة التثخيصية المصنعة باعيم: Bio-X Diagnostics حيث تم اجر اء الاختبار حسب التعليمات الخاصة بالشركة.

تقييم النتائج :

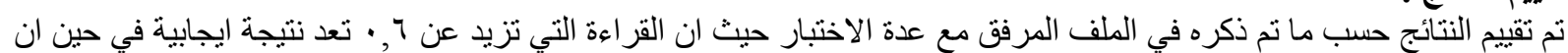

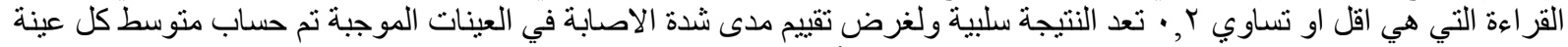
موجودة في حفرتين مع حساب متوسط السيطرة الايجابية ايضآ ضمن المعادلة التئة الاتية :

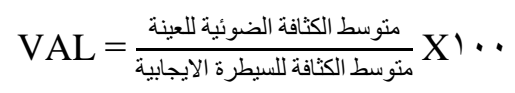

وتم إحتساب شدة الاصابة حسب ما هو مرفق كالاتي : إنابة

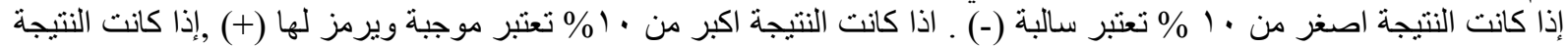

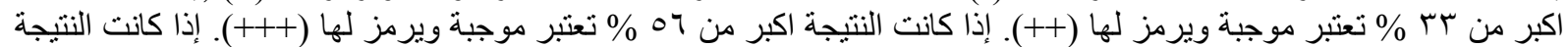

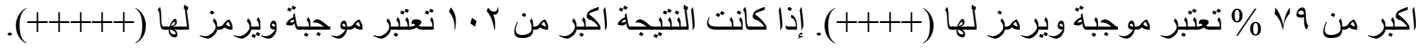




\section{RESULTS}

النتائــج

نتائج الاختبارات المصلية

نتائج التحري عن اضداد الفيروس الغدي البقري النمطــــ باستخدام اختبار الممتز المناعي المرتبط بالانزيم

الجدول ا : يبين نسبة الاصسابة الاجمالية بالفيروس الغدي البقري النمطــــ في العجول ولمرتين متتاليتين من جمع العينات باستخدام اختبار الممتز المناعي المرتبط بالانزيم الإنيم

\begin{tabular}{|c|c|c|}
\hline عدد الحيو انات الموجبة للاختبار & عدد الكلي للحيو انات المفحوصة & اختبار الممتز المناعي \\
\hline $\mathrm{a} \leq \Lambda(Y \leq \%)$ & \multirow{2}{*}{$r}$. & الفحص الاول \\
\hline a $\circ V(Y \wedge, 0 \%)$ & & الفحص بعد ا ب يوم \\
\hline
\end{tabular}

الاختلاف في الاحرف (a ,b) يعني وجود فرق معنوي تحت مستوى احتمال (0.05) بعم (p)

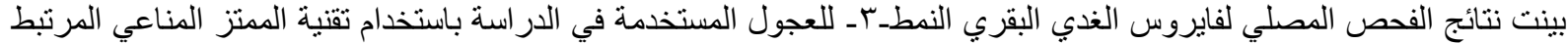

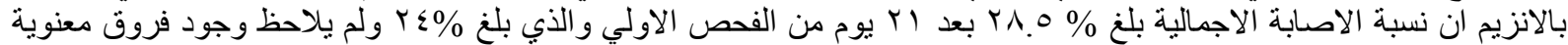
و اضحة بين الفحصين.

الجدول ؟ : علاقة العمر بالاصـابة بالفيروس الغدي البقري النمط ــــ باستخدام اختبار الممتز المناعي المرتبط بالانزيم.

عدد الحيو انات الموجبة لاختبار الممتز المناعي المرتبط بالانزيم المبانيم للمرة الثانية بعد الب البط بوالاتزا (نسبة الاصدابة \%)

\section{عدد الحيوانات الموجبة

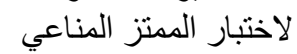
المرتبط بالانزيم للمرة الأولى لئى

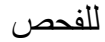
(نسبة الاصنابة \%)

\begin{tabular}{|c|c|c|c|}
\hline$r \leq(0 r . r \%)^{a}$ & $19(\leqslant Y . Y \%)$ & $\leqslant 0$ & 19_9 اشهر \\
\hline $17(Y Y .0 \%)^{b}$ & $10(Y) .1 Y \%)$ & VI & من · 1 اشهر -سنة \\
\hline$T r(T \cdot . T \%)^{b}$ & $11(1 \vee, \leqslant \%)$ & 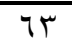 & من سنة ـ سنة ونصف \\
\hline$\varepsilon(.19 \%)^{b}$ & $r(1 \varepsilon . r \%)$ & YI & من سنة ونصف ـ Y سنة \\
\hline OV $($ Y ..$\%)$ & $\varepsilon \wedge(Y \leqslant \%)$ & r.. & المجموع \\
\hline
\end{tabular}

بينت النتائج وجود فروق معنوية واضحة في معدلات الاصدابة بالفيروس، حيث كانت اعلى نسبة اصابة في الفئات العمرية الاصغر

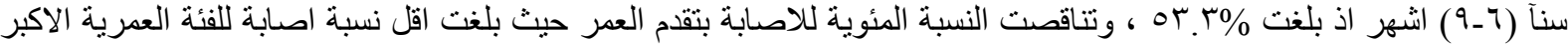

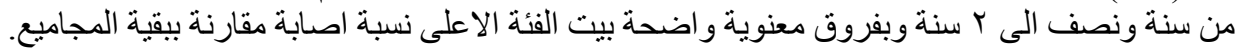

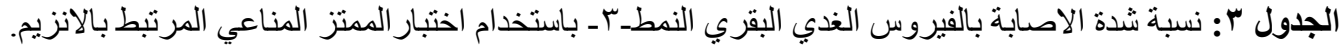

\begin{tabular}{|c|c|c|c|c|c|c|c|}
\hline \multicolumn{5}{|c|}{ النسبة المئوية لثدة الاصابة باستخدام اختبار الممتز المناعي المرتبط بالانزيم } & \multirow{2}{*}{ 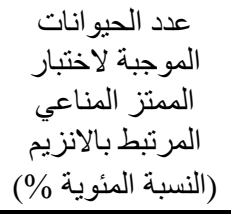 } & \multirow{2}{*}{ المفيو انات } & \multirow[b]{2}{*}{ 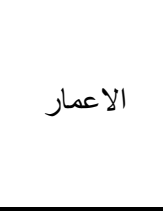 } \\
\hline 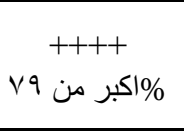 & $\begin{array}{l}++ \\
\text { اكبر من } \\
07 \%\end{array}$ & 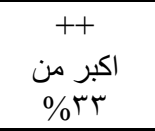 & $\begin{array}{c}+ \\
+ \text { اكبر من } 1 . \% \\
1 \%\end{array}$ & اقل من · إ\% & & & \\
\hline $1 \cdot(r,, Y \%)$ & $V(10.00 \%)$ & (1). & $I(r, Y \%)$ & Y) $(\leqslant \neg, 7 \%)$ & $r \leqslant(0 r . r \%)$ & $\leq 0$ & 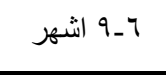 \\
\hline$\varepsilon(0,7 \%)$ & $\wedge(1) . r \%)$ & $r(Y . \wedge \%)$ & $r(r . \wedge \%)$ & $00(\vee \vee . \leqslant 7 \%)$ & $17(Y T .0 \%)$ & VI & من · مانة اشهر - \\
\hline$r(\varepsilon, \vee \%)$ & $1(1.0 \%)$ & $\varepsilon(\urcorner . r \%)$ & $\circ(\vee .9 \%)$ & $0 .(\vee ৭ . r \%)$ & $I r(r \cdot . T \%)$ & חז & من سنة - سنة \\
\hline \multirow[t]{2}{*}{$\cdot(\cdot \%)$} & 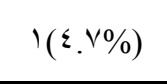 & I $(\varepsilon . \vee \%)$ & $r(9.0 \%)$ & $Y \vee(\wedge \cdot .9 \%)$ & $\leqslant(19, \leqslant \%)$ & Y) & ونصف سنة سنة \\
\hline & & & & & $O \vee(\uparrow \wedge, \Delta \%)$ & $r \ldots$ & \\
\hline
\end{tabular}




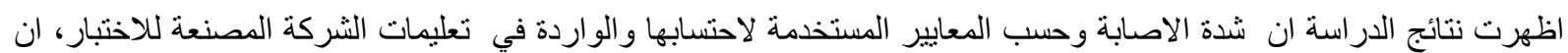

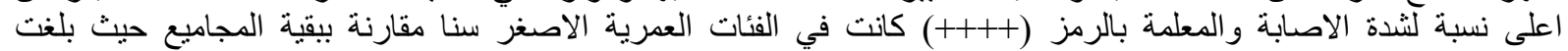

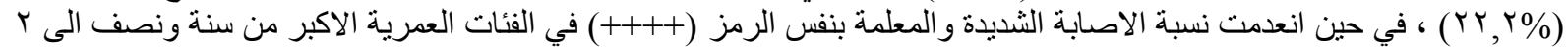

الجدول ؛ : علاقة منشأ العجول بالاصـابة بفيروس الغدي البقري النمط ــــ باستخدام اختبار الممتز المناعي المرتبط بالانزيم

\begin{tabular}{|c|c|c|}
\hline عدد الحيو انات الموجبة لاختبار الممتز المناعي المرتبط بالانزيم & عدد الحيو انات المفحوصة & المنشأ \\
\hline$\wedge(\backslash \vee . \vee \%)^{a}$ & $\leqslant 0$ & محلي \\
\hline$\varepsilon q(\Gamma) .7 \%)^{b}$ & 100 & مستورد \\
\hline
\end{tabular}

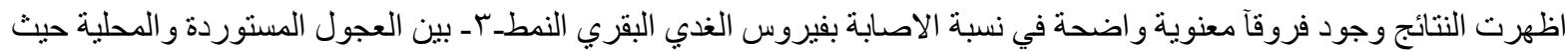

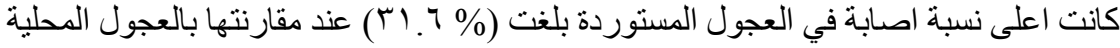

الجدول ه: يبين نسبة شدة الاصدابة في الحيوانات المحلية والمستوردة باستخدام اختبار الممتز المناعي المرتبط بالانزيم.

\begin{tabular}{|c|c|c|c|c|c|c|c|}
\hline \multicolumn{5}{|c|}{ النسبة المئوية لثدة الاصابة باستخدام اختبار الممتز المناعي المرتبط بالانزيم } & \multirow{2}{*}{ 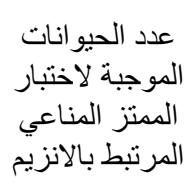 } & \multirow[b]{2}{*}{ عدد الحيو انات } & \multirow[b]{2}{*}{ المنشأ } \\
\hline $\begin{array}{c}++++ \\
\text { اكبر من و \% }\end{array}$ & $\begin{array}{l}\text { اكبر من } \\
\text { \% } 4++1\end{array}$ & 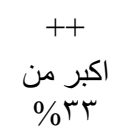 & $\begin{array}{c}+ \\
\text { اكبر من } \\
\text { \% }\end{array}$ & اقل من · إ\% & & & \\
\hline$\cdot(\cdot \%)$ & $r(\varepsilon, \leqslant \%)$ & $\varepsilon(\wedge, \wedge \%)$ & $r(\varepsilon, \varepsilon \%)$ & rV(^r. r\%) & $\wedge(\mid \vee . \vee \%)^{\mathrm{a}}$ & $\leq 0$ & محلي \\
\hline$r r(1 \leqslant, 1 \%)$ & $10(9,7 \%)$ & $o(r, r \%)$ & $V(\varepsilon .0 \%)$ & 1. $(\neg \wedge . r \%)$ & $\varepsilon q(\Gamma), 7 \%)^{b}$ & 100 & مستورد \\
\hline
\end{tabular}

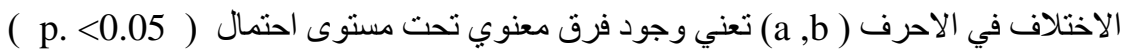

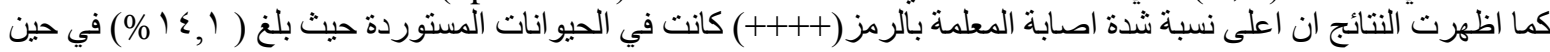

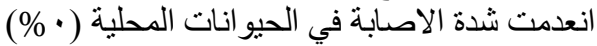

\section{DISCUSSION المناقشة}

تعد الاصدابات التنفسية في الابقار و الناجمة عن المسببات الفيروسية من اكثر المشاكل التي تو اجه سلسلة الانتاج في المجتر ات الكبيرة ،

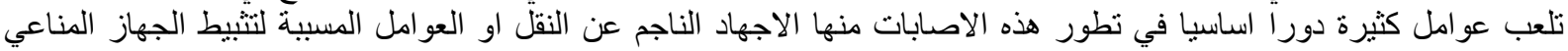

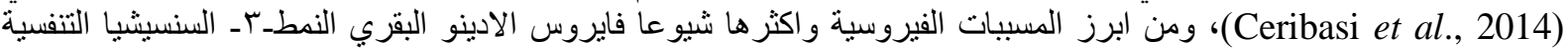

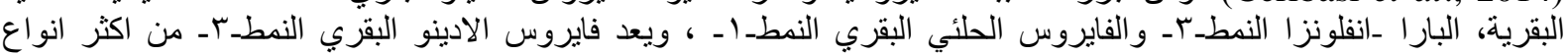

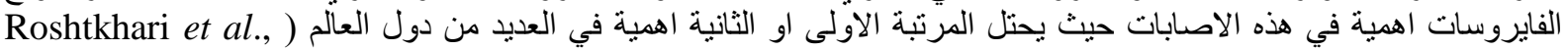

بينت نتائج الدراسة للتقصي عن نسبة الاصابة بفيروس الادينو البقري النمط ــــ في العجول باستخدام تقنتية الممتز المناعي المرتبط

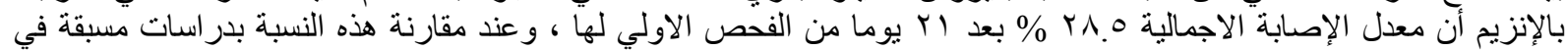

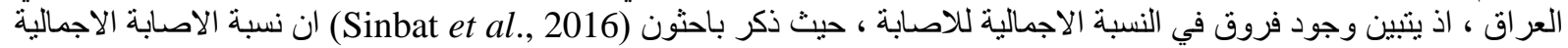

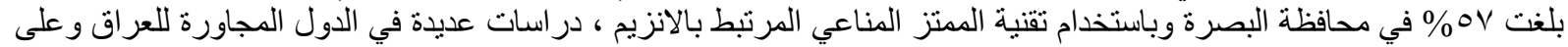

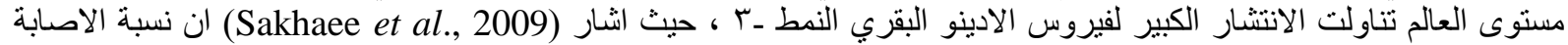

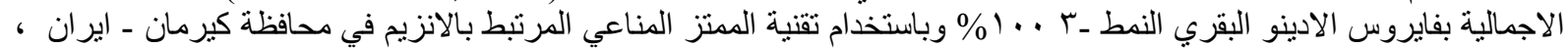

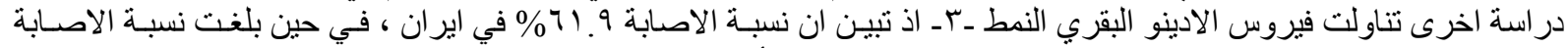

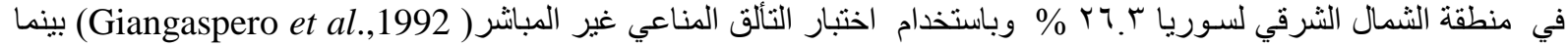

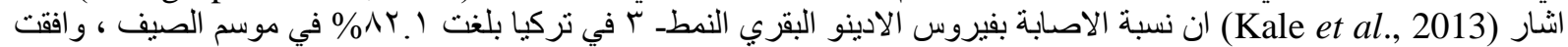

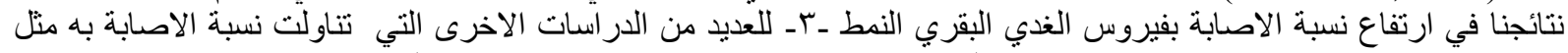

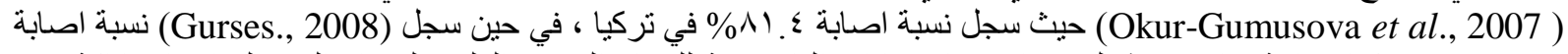

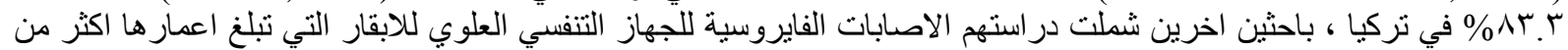

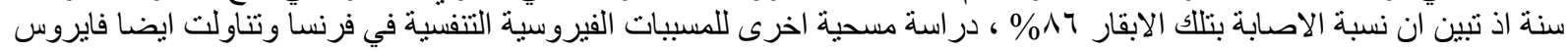

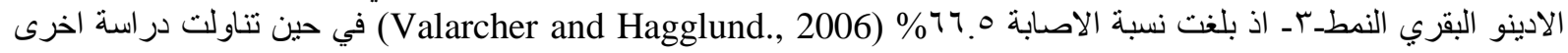




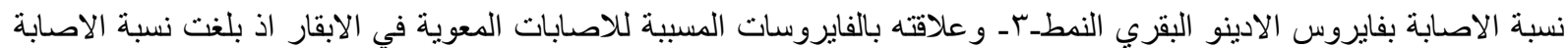

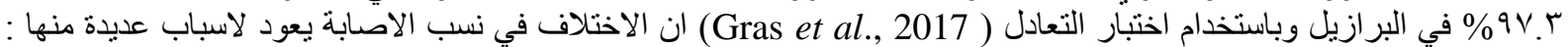

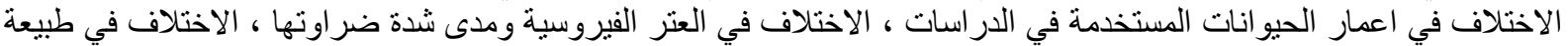

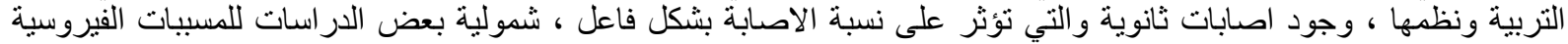

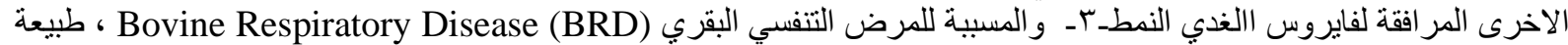
انتقاء الحيو انات و اهداف كل در اسة ( Elvander et al., 1996 ) ، در اسة اخرى في فنلندا تتاولت المسببات الفايروسية و الجرثومية

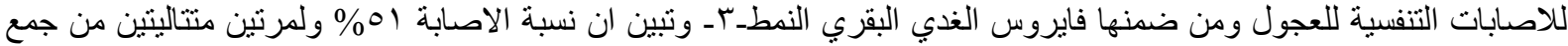

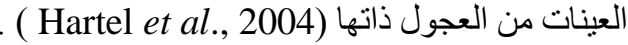

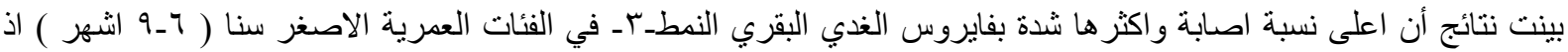

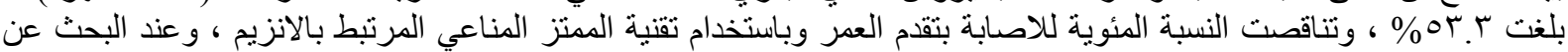

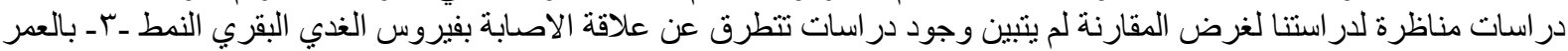

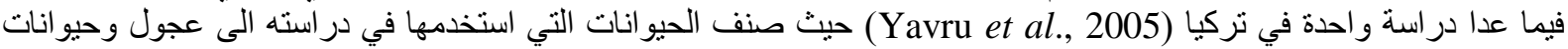

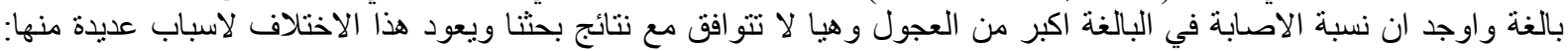

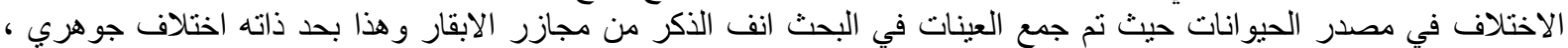

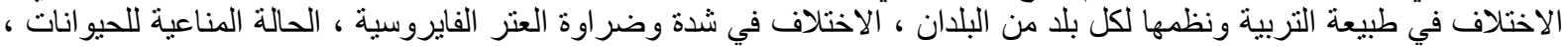

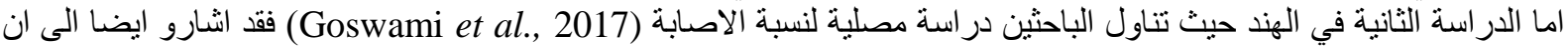

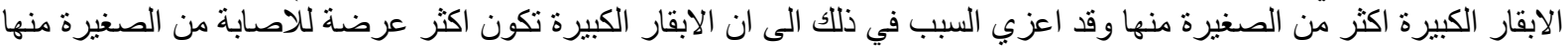

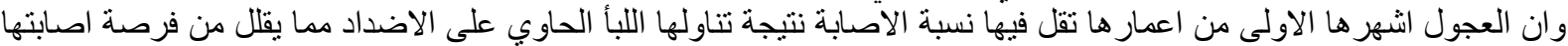
و اعطاءها مناعة تقاوم فيها العديد من الاصنابات التنفية التهابة الفايروسية.

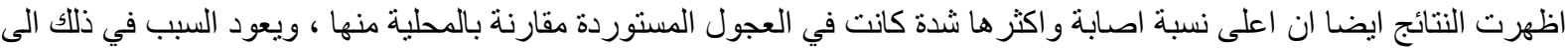

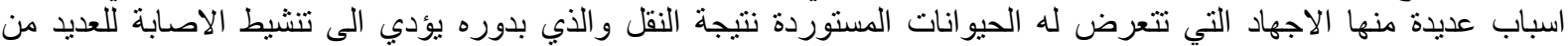

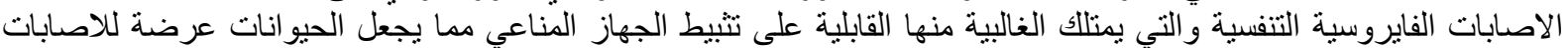

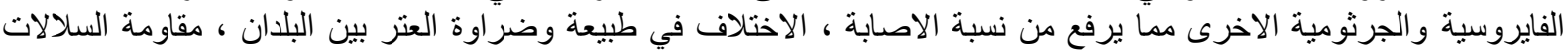

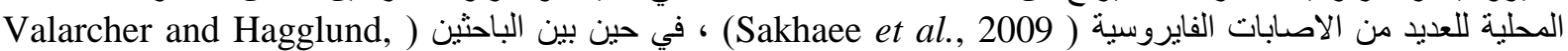

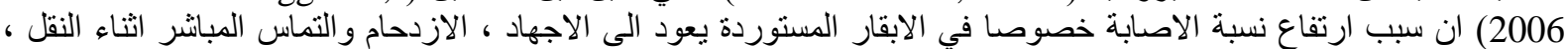

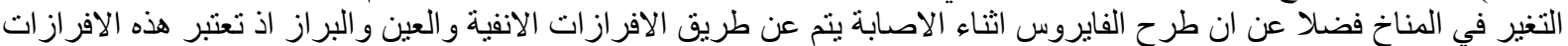

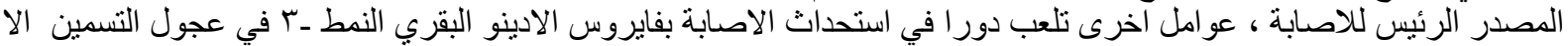

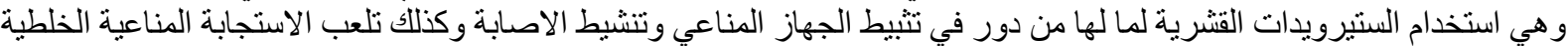

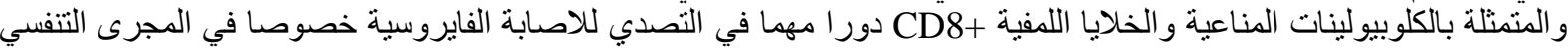

للحيو انات المصابة (Narita et al., 2003)

\section{REFERENCES}

المـراجـ

Anderson, D.E. and Rings, M.D. (2009): Current Veterinary Therapy Food Animal Practice, $5^{\text {th }}$ Ed. Saunders, St. Louis Mo..Pp: 179

Ali, O.C.; Songül, C. and Mustafa, O. (2016): Immunohistochemical detection of bovine herpesvirus type 1 and bovine adenovirus type 3 antigens in frozen and paraffi nized lung sections of pneumonic sheep and goats. Veterinarski arhiv. 86 (1): 9-21.

Al-Hammadi, M.A. and Hemida, M.G. (2014): Sero-Prevalence of Common Bovine Respiratory Viral Diseases In Saudi Arabia. Med. J.60(140).76-81.

Ceribasi, A.O.; Ozkaraca, M.; Ceribasi, S. and Ozer, H. (2014): Histopathologic immunoperoxidase and immunofluorescent examinations on natural cattle pneumonia originated from Parainfluenza type3, Respiratory Syncytial virus, Adenovirustype 3 and Herpesvirus type 1. Revue Méd. Vét.,165: 201-212.

Elvander, M. (1996): Severe respiratory disease in dairy cows caused by infection with bovine respiratory syncytial virus. Vet. Rec., 138: 101-105.

Giangaspero, M.; Vacirca, G.; Vanopdenbosch, E. and Blondeel, H. (1992): Epidimological survrey on viruse diseases of cattle in north Syria. Tropicul Tura.,10(2): 55-57.

Goswami, P.; Banga, H.S.; Mahajan, V.; Singh, N.D.; Deshmukh, S. and Brar, R.S. (2017): Detection of Multiple Antibodies and Risk Factor Association of Common Respiratory Viruses in the State of Punjab, India. Int. J.Curr. Microbiol. App. Sci., 6(3): 567-577. 
Gurses, E. (2008): Sigirlarin viral solunum yolu enfeksiyonlarinin serolojik olarak arastirilmasi, University of Selçuk, Turkey, MSc. Thesis.

Gras, C.K.; Demoliner, M.; Eisen, A.K.A.; Spilki, FR. and Henzel, A. (2017): Seroprevalence of Bovine Adenovirus and Enterovirus Antibodies Reveals Different Infection Dynamics in Cattle Herds. Acta Scientiae Veterinariae.,45: 1-6.

Hakhverdyan, M.; Mamadatokhonova, M. and Belák, S. (2016): Development of a Taq Man Real Time PCR Assay for the Rapid Detection of Bovine Adenovirus Serotypes in Cattle. J. Vet Med Res 3(3): 1-7.

Hartel, H.; Nikunen, S.; Neuvonen, E.; Tanskanen, R.; Kivelä, SL.; Aho, R.; Soveri, T. and Saloniemi, H. (2004): Viral and bacterial pathogens in bovine respiratory disease in Finland. Acta Vet Scand 45: 193-200. http://dx.doi.org/10.1186/1751-0147-45-193.

Kale, M.; Ozturk, D.; Hasircioglu, S.; Pehlivanoglu, F. and Turutoglu, H. (2013): Some viral and bacterial respiratory tract infections of dairy cattle during the summer season. Acta Veterinaria (Beograd). 63. (2-3) 227-236.

Kulshreshtha, V. (2009): Molecular characterization of 33k protein of bovine adenovirus type 3. PHD Thesis. Department of Veterinary Microbiology, University of Saskatchewan. Saskatoon.

Makadiya, N. (2013): Functional Characterization Of 100K Protein of Bovine adenovirus type 3. MSc. Desseration. Department of Veterinary Microbiology, University of Saskatchewan. Saskatoon.

Mamadatokhonova, G. (2006): Detection of Adenoviruses in cattle. MSc. desseration. Faculty of Veterinary Medicine and Animal Science, Swedish University of Agricultural Sciences. Uppsala.

Mittal, S.K.; Middleton, D.M.; Tikko, S.K.; Prevec, L.; Graham, F.L. and babiuk, L.A. (1996): Pathology and immunogenicity in the cotton rat (sigmodon hispidus) model after infection with a bovine adenoviruse type 3 recombinant viruse expressing the firefly luciferase gene. Journal of General Virology.,77: 1-9.

Narita, M.; Yamada, M.; Tsuboi, T. and Kawashima, K. (2003): Bovine Adenovirus Type 3 Pneumonia in Dexamethasone-treated Calves. Vet Pathol 40: 128-135.

Okur-Gumusova, S.; Yazici, Z.; Albayrak, H. and Cakiroglu, D. (2007): Seroprevalence of bovine viral respiratory diseases, Acta Vet (Beograd), 57, 11-6.

Rai, A. (2005): Methods in Veterinary Virology, Indian Veterinary Research Institute, India, Pp: 5052.

Reddy, P.S.; Idamakanti, N.; Chen, Y.; Whale, Babiuk, T.A.; Mehtali, M. and Tikoo, S.K. (1999): Replication-Defective Bovine Adenovirus Type 3 as an Expression Vector. Journal of Virology., 73 (11): 9137-9144.

Roshtkhari, F.; Mohammadi, G. and Mayameei, A. (2012): Serological evaluation of relationship between viral pathogens (BHV-1, BVDV, BRSV, PI-3V, and Adeno3) and dairy calf pneumonia by indirect ELISA. Trop Anim Health Prod ,41(3): 1105-1110.

Sakhaee, E.; Khalili, M. and Kazeminia, S. (2009): Serological study of bovine viral respiratory diseases in dairy herds in Kerman province Iran. Iranian Journal of Veterinary Research, Shiraz University.10(1): 49-53

Sinbat, S.A.; Al-Rodhan, A.M. and Othman, R.M. (2016): Molecular and Serological Detection of Bovine Adenovirus Type-3 In Basra Province. Basrah Journal of Veterinary Research.,15(3): 108-118.

Valarcher J.F. and Hagglund, S. (2006): Viral respiratory infections in cattle, Proceedings of XXIVth World Buiatric Congress, Nice, France, 384-97.

Yavru, S.; Simsek, A.; Yapkic, O. and Kale, M. (2005): Serological Evaluation of Viral Infections in Bovine Respiratory Tract. Acta Veterinaria., 55 (2-3): 219-226.

Zhang, P.; Xue, Q.; Ma, J.; Ren, J.; Xia, S.; Zhang, L.; Wang, W.; Tikoo, S.K. and Du, E. (2017): Bovine adenovirus type 3 virions cannot be rescued invivo after full-length viral genome transfection in the absence of detectable polypeptide IX.J. Vet Sci.,18(2):217-227. 